\title{
PROBLEMAS COMPORTAMENTAIS DE CRIANÇAS COM TDAH NO ÂMBITO ESCOLAR
}

\author{
Kátia de Assis Pereira ${ }^{1}$ \\ Renan Valério Eduvirgem ${ }^{2}$ \\ Maria Luiza de Medeiros Monteiro ${ }^{3}$
}

PEREIRA, K. de A.; EDUVIRGEM, R. V.; MONTEIRO, M. L. de M. Problemas comportamentais de crianças com TGAH no âmbito escolar. EDUCERE - Revista da Educação, Umuarama, v. 17, n. 1, p. 79-92, jan./ jun. 2017

RESUMO: Esse trabalho tem como objetivo mostrar alguns dos problemas comportamentais presentes nas crianças que possuem o Transtorno de Déficit de Atenção/Hiperatividade (TDAH), segundo Barkley (2008) o atual termo usado para denominar os significativos problemas apresentados por crianças quanto à atenção, a impulsividade e a hiperatividade, sendo assim as crianças com TDAH, demonstraram dificuldades em terminar uma atividade ou trabalho, ficam aborrecidas com tarefas não estimulantes ou rotineiras e não sabem fazer transição de uma atividade para outra. Também possuem comportamento imprevisível, não aprendendo com os erros passados, têm problemas de sono, são difíceis de serem agradadas, algumas vezes agressivas, não tem noção do perigo, frustram-se com facilidade, não reconhecem limites e apresentam dificuldades no relacionamento com outras crianças ou com os estudos, por isso é necessário que este se confirme por seis meses e por duas situações diferentes no cotidiano da criança, não somente na escola, mas sim, podendo ser analisados dentro da casa das mesmas, ainda levando em consideração que as queixas podem ser causadas por outros distúrbios ou podem representar uma reação da criança a outro problema. Chegou-se aos resultados por meio de uma pesquisa qualitativa produzida com a utilização de uma

DOI: https://doi.org/10.25110/educere.v17i1.2017.6285

1E-mail: vida1979@hotmail.com

${ }^{2}$ Graduado em Geografia (Bacharelado - 2015) e (Licenciatura - 2015) na Universidade Estadual de Maringá - UEM. Atualmente cursa Mestrado em Geografia pelo Programa de Pós-graduação em Geografia (PGE-UEM), também é aluno da turma de Especialização em Arqueologia ofertada pelo (DGE-UEM). Bolsista da Fundação CAPES. E-mail: georenanvalerio@gmail.com

${ }^{3}$ E-mail: maria_luizamonteiro@hotmail.com 
revisão bibliográfica, concomitante a dialética da temática.

PALAVRAS-CHAVE: Distúrbio; Família; Sociedade.

\title{
BEHAVIORAL PROBLEMS OF CHILDREN WITH ADHD IN SCHOOLS
}

\begin{abstract}
This paper aims to show some of the behavioral problems present in children who have Attention Deficit/Hyperactivity Disorder (ADHD), according Barkley (2008) The current term used to refer to the significant problems presented by children for attention, impulsivity and hyperactivity, so children with ADHD, have had difficulty in completing an activity in the job, get bored with tasks not stimulants or routine and do not know how to make the transition from one activity to another. They also have unpredictable behavior, not learning from past mistakes, they have sleep problems, are difficult to be relationship, and sometimes aggressive, they have no concept of danger, frustrate themselves easily, do not recognize boundaries and have difficulties in relationship with other children or with studies, so it is necessary that this point be confirmed by six months and for two different situations in daily life of the child, not only in school, but it can be analyzed inside their houses, even taking into consideration that complaints can be caused by other disorders or may represent a reaction of the child to another problem. The results obtained through a qualitative research produced with the use of a bibliographic review, concomitant to dialectics of theme.
\end{abstract}

KEYWORDS: Disturbance; Family; Society.

\section{PROBLEMAS CONDUCTUALES DE NIÑOS CON TDAH EN EL ENTORNO ESCOLAR}

RESUMEN: Esta investigación pretende mostrar algunos de los problemas de comportamiento presentes en niños portadores de Trastorno de Déficit de Atención/Hiperactividad (TDAH), según Barkley (2008) el actual término usado para denominar los significativos problemas presentados por niños cuanto a la atención, impulsividad e hiperactividad. Los niños con TDAH demostraron dificultades en terminar una actividad o trabajo, se aburren con tareas no estimulantes o rutineras y no saben cómo 
hacer transición de una actividad para otra. También tienen comportamiento imprevisible, no aprendiendo con los errores pasados, tienen problemas de sueño, son difíciles de ser agradados, algunas veces agresivos, no tienen noción de peligro, se frustran con facilidad, no reconocen límites y presentan dificultades en relacionamientos con otros niños o con los estudios. Por ello es necesario que esto se confirme por seis meses y por dos situaciones diferentes en el cotidiano del niño, no sólo en la escuela, sino pudiendo ser analizados dentro de las casas de los mismos, aun llevando en consideración que las quejas pueden ser causadas por otros disturbios o pueden representar una reacción del niño a otro problema. Se ha llegado a los resultados por medio de una investigación cualitativa producida con la utilización de una revisión bibliográfica, concomitante a la dialéctica de la temática.

PALABRAS CLAVE: Disturbio; Familia; Sociedad.

\section{INTRODUÇÃO}

Em toda sociedade, independente da época e do lugar, encontrava-se crianças desatentas e hiperativas que apresentavam comportamentos impulsivos, porém esses acontecimentos específicos ainda não eram classificados como um transtorno.

As primeiras notícias sobre o TDAH começaram a surgir no século XIX, de acordo com Silva (2009), George Fredrick Still realizou palestras em 1902, nas quais falou sobre crianças que, dentre outros aspectos, apresentavam-se agressivas, desafiadoras e hiperativas. Em algumas de suas pesquisas ele rotulou os pais como portadoras de "defeito de controle moral", atribuindo-lhes a responsabilidade do comportamento dos filhos.

Foi a partir da década de 1960 que começaram a surgir preocupações acerca desse possível transtorno, no início da década de 1970 houve a primeira definição nominal perante os casos de TDAH, que também passou a incluir a hiperatividade dentro de seu quadro diagnóstico, que nada mais é do que sintomas sutis de distração e impulsividade. Com isso, a observação perante a importância do TDAH se torna algo realmente discutível já que, o tema é sem dúvidas bastante relevante e divulgado em nossa sociedade nos dias atuais, pois antigamente apenas os pais das crianças que tinham o transtorno eram orientados sobre o assunto dife- 
rentemente de hoje, em que o TDAH já está catalogado pela Organização Nacional de Saúde pela Organização Mundial de Saúde (OMS).

O Transtorno de Déficit de Atenção com Hiperatividade é um transtorno neurológico cada vez mais diagnosticado nas crianças da nossa sociedade. Possivelmente pode ser concebido por meio de causas genéticas, todavia estudos revelam que o mesmo também pode ter outras causas como, o uso de substâncias ilícitas durante a gestação, sendo elas as mais comuns, a nicotina e o álcool, que acabam gerando o sofrimento fetal e, ocasionando complicações na hora do parto. A exposição da criança a elementos químicos, principalmente ao chumbo junto de problemas familiares, também podem ser um dos precursores do transtorno que não se apresenta somente na infância, na maioria das vezes acompanha o indivíduo por toda a sua vida.

Muitos educadores não possuem um preparo adequado para trabalhar com esses alunos em sala de aula, os que apresentam o Transtorno de Déficit de Atenção com ou sem Hiperatividade, prejudicando assim toda a instituição em que o aluno está inserido. O educador ao se deparar com esse tipo de contexto não deve se desesperar, mais sim proporcionar ao aluno que apresenta o transtorno, algumas maneiras diferenciadas e interativas durante seu magistério que consigam chamar a atenção do mesmo durante as aulas, estimulando cada vez mais seu desenvolvimento cognitivo, conseguindo assim alcançar resultados mais satisfatórios durante o processo de ensino-aprendizagem.

Mesmo sem uma formação adequada o professor se torna o principal aliado perante ao diagnóstico do TDAH no aluno, já que por muitas vezes a família não consegue detecta-lo sozinha por ter um convívio restrito com a criança, já que é na escola que o aluno passa a maior parte do seu tempo, tendo uma relação extremamente ligada ao seu professor, principal observador das atividades rotineira que o discente apresenta, com isso ele consegue estar mais apto em detectar se algo de errado está acontecendo com seu pupilo e imediatamente alertar a família.

Devido a esses fatores esse trabalho tem como objetivo discutir os problemas encontrados dentro das salas de aula por alunos com TDAH, apontando como princípios básicos a desatenção, impulsividade e hiperatividade, sintomas comuns de quem apresenta o devido transtorno, buscando maneiras diferenciadas e criativas usadas como ferramentas 
para facilitar o trabalho pedagógica do professor perante a criança que muitas vezes é barrada cognitivamente e fisicamente pelo TDAH.

\section{METODOLOGIA}

Essa pesquisa foi realizada por meio de uma revisão bibliográfica sendo selecionados textos que se encaixavam de acordo com o tema desse artigo, os trabalhos que embasaram essa pesquisa qualitativa foram dissertações, monografias e artigos científicos.

Neste estudo foi empregada a metodologia delineada por Cervo e Bervian (1983) em que a pesquisa bibliográfica explica um problema por meio de referenciais teóricos. Buscamos, primeiramente, apresentar o Transtorno de Déficit de Atenção com Hiperatividade, em seguida pontuar as causas e consequências, e, por fim foram denotados meios de mitigação ou tratamento do TDAH, enfatizando a criança, o professor, o educador, e, a família.

\section{TRANSTORNO DE DÉFICIT DE ATENÇÃO COM HIPERATIVI- DADE (TDAH): CAUSAS E CONSEQUÊNCIAS}

Podemos verificar que o TDAH é cada vez mais diagnosticado nas crianças. Para Vasconcelos et al., (2003, p.68) “os estudos epidemiológicos mais rigorosos definiram taxas de 4 a $12 \%$ da população geral de crianças de 6 a 12 anos de idade", ou seja, 4 a 12\% da população geral das crianças possuem TDAH, porém a pesquisa ainda não para por ai, os pontos mais agravantes mostram ainda que o transtorno tem aumentado na vida dos adolescentes e dos adultos, o "impacto do TDAH na comunidade é ainda maior quando se considera que este transtorno acarreta morbidade continuada na adolescência ( $85 \%$ das crianças) e na idade adulta (50 a 70)". (VASCONCELOS et al., 2003).

O TDAH é bastante polêmico na atualidade, e por isso essa temática deve ser trabalhada minuciosamente para a compreensão não somente dos aspectos gerais, mas também das peculiaridades. O Transtorno de Déficit de Atenção e Hiperatividade ganha atenção após a década de 80 do século passado:

A partir dos anos 80, o TDAH - Transtorno de Déficit de Aten- 
ção e Hiperatividade vem ocupando lugar de destaque na vida dos pais e também de profissionais de saúde mental, sendo considerado o principal distúrbio psicológico em crianças, porém sem muita divulgação. Hoje como crescimento dos grupos de apoio e com uma considerável exposição na mídia, mais crianças estão sendo diagnosticadas e tratadas corretamente. Carvalho et al. (2012, p. 2)

Desse modo, é possível enfatizar a importância da discussão do TDAH na contemporaneidade, um tema importante para ser discutido e discriminado dentro do meio em que estamos inseridos.

No âmbito escolar não se difere de outros lugares que manifestam seus desinteresse pelo causo, muitas vezes a criança que apresenta esse tipo de transtorno, pode ser considerada como uma criança que não contém um bom comportamento social perante a instituição de ensino, não que em muitos casos não seja, entretanto, o aluno pode estar apresentando alguns sintomas do Transtorno de Déficit de Atenção e Hiperatividade, segundo Mello e Cardoso (2015, p.2) “O TDAH não deve ser avaliado como procedimento inconveniente, ou falha na educação, pois existe um comprometimento funcional da vida profissional, acadêmica e de relacionamento".

O diagnóstico do TDAH só pode ser feito por um neurologista ou algum médico especialista na área, contudo o professor tem um papel muito importante nessa hora já que, consegue relatar alguns indicativos do transtorno, vários desses sintomas podem ser, agitações constantes, não se fixando somente em um lugar, por muitas vezes parece que não está ouvindo o que os outros falam, se distraindo constantemente com qualquer detalhe, não apresentando paciência para esperar o fim das atividades no decorrer da aula e por muitas vezes, acaba se tornando agressivo.

Quando o TDAH não é tratado adequadamente ainda na infância momento propício para surgirem os primeiros sinais, ao se tornar adulto o indivíduo continuará tendo uma grande desatenção com as coisas do cotidiano, principalmente no trabalho, assim como as crianças que possuem o transtorno, com essas características o mesmo terá dificuldades ao analisar seus próprios comportamentos sem a ajuda de um profissional capacitado, além de tudo ele pode estar conectado a outros problemas como 
drogas, consumo alto de álcool, problemas com ansiedade e depressão.

O TDAH também pode estar associado com outras doenças neurológicas tanto em crianças como em adultos:

Estudos de comorbidade revelaram taxas elevadas de ocorrência com outros transtornos psiquiátricos, em especial os transtornos do humor, transtornos ansiosos e os transtornos disruptivos do comportamento. Na associação do TDAH com outros transtornos, além das dificuldades causadas ela soma de sintomas de mais um transtorno, há também um aumento na prevalência de complicações em relação ao TDAH isolado. (POSSA; SPANEMBERG; GUARDIOLA, 2005, p. 480).

Muitas vezes o TDAH apresentado por crianças e adultos é acompanhado de outros problemas neurológicos muito sérios e isso acaba dificultando ainda mais o diagnóstico do transtorno. Além disso, temos uma barreira cultural alastrada em nosso meio que impede que o diagnóstico neurológico seja feito de maneira concisa, pelo fato de existir uma crença em que as crianças são incapacitadas de adquirirem algum tipo de problema emocional e com isso, a sociedade se hesitou por muito tempo a acreditar que não existisse um transtorno com essas características, que inicialmente era analisado como um transtorno peculiar nos pequenos, principalmente nos meninos, ainda tinham a certeza de que os sintomas desapareceriam em um passe de mágica na idade adulta, o que raramente acontece.

Os outros distúrbios neurológicos que acompanham o TDAH são comprovados hoje por estudos que os consideram não apenas como um problema que chega a atingir o indivíduo em sua forma cognitiva, mas sim também atinge aspectos emocionais, comportamentais e afetivos.

Lembramos que "o TDAH pode-se manifestar em grau leve ou grave. Nem todas as pessoas mostram todos os sintomas, nem todas as pessoas apresentam os sintomas com o mesmo nível de gravidade" (CARVALHO et al., 2012, p. 4), devido a isso, são constantes os questionamentos em vista do papel da escola no processo de ensino-aprendizagem diante do transtorno presente na criança, pois mesmo sendo bem claras as dificuldades de aprendizagem que o aluno apresenta, ainda não são convincentes os motivos que, muitas vezes, levam ao fracasso escolar 
diante do ensino-aprendizagem.

Um dos vilões que compromete o aprendizado do discente que possui TDAH é o comprometimento do sono que causa alterações no mesmo, como já sabemos "os transtornos do sono podem comprometer consideravelmente a qualidade de vida da criança" (CARVALHO et al., 2012 , p. 5). O sono é necessário para o desenvolvimento físico, cognitivo e psicológico de qualquer pessoa e ao afetá-lo é evidente o surgimento de sequelas capaz de prejudicar diretamente a vida de qualquer ser humano.

Ainda diante da visão de Carvalho et al., (2012) a criança que possui o transtorno necessita, inevitavelmente, receber informações e conceitos referente a sua própria idade, fazendo com que o professor que acompanha o aluno, junto dos profissionais da saúde mental e pediatras, adquiram o dever de reconhecer os sintomas básicos que acompanham o portador.

O professor por ser um dos grandes observadores do aluno e deve ficar atento diante dos sintomas que podem ser apresentados mediante aos comportamentos do próprio, pois é esse profissional que o conhece como poucos, mantendo um olhar geral na turma e ao mesmo tempo individual, diferentemente dos outros profissionais que apresentam ou enxergam o paciente fora de sua rotina e na realidade que se insere.

Os professores e educadores possuem papel fundamental para o auxílio na identificação dos indícios no aluno como já citado, de acordo com os estudos de Barkley e Gordon (2002) o TDAH continua na vida adulta em torno de $60 \%$ a $70 \%$ dos registros. Entretanto, os debates com alusão há diagnósticos de TDAH em adultos, são discutíveis (MCCOUGH; BARKLEY, 2004). Todavia, há estudos que salientam que o TDAH persiste ao longo da vida (BIEDERMAN et al., 2000; MATTOS et al., 2006; MATTOS et al., 2006).

Temos que levar em consideração que "o reconhecimento de que a maioria dos portadores de TDAH não supera seus sintomas, pode proporcionar diagnóstico e tratamentos eficazes para muitos adultos também portadores deste transtorno" (CARVALHO et al., 2012, p. 6), por isso não devemos fechar os olhos para qualquer sintoma suspeito que a criança apresentar. 


\section{TÉCNICAS CAPAZES DE AMENIZAR OU TRATAR O TDAH}

Existem tipos diferentes de TDAH, que são classificados em três, os que apresentam predomínio de sintomas de desatenção, os que possuem predomínio de sintomas de hiperatividade/impulsividade e o Combinado. Estudos mostram que o distúrbio de sintomas de desatenção é predominante em meninas e, com isso consta uma taxa mais elevada de prejuízo no processo de ensino-aprendizagem para elas.

A criança que tem o distúrbio voltado para hiperatividade e impulsividade, também goza mediante a uma agressividade maior do que as que possuem os sintomas dos outros tipos de TDAH, com isso essas crianças acabam sendo rejeitas pelos amigos da escola. Os sintomas são propícios para todos os três tipos de distúrbios, contudo os indivíduos que as características do combinado são mais fortes, podendo apresentar um maior prejuízo no funcionamento global ao ser comparado com os outros dois tipos:

A proporção entre meninos e meninas afetados varia de aproximadamente 2:1 em estudos populacionais ato 9:1 em estudos clínicos. A diferença entre essas proporções provavelmente se deve ao fato de as meninas apresentarem mais transtorno de déficit de atenção hiperatividade (TDAH) com predomínio de desatenção e menos sintomas de conduta em comorbidade, causando menos incômodo às famílias e à escola, e, portanto, serem menos encaminhadas a tratamento. (ROHDE; HALPERN, 2004, p. 62).

Diante disso, a família da criança com o TDAH, assim como toda a equipe pedagógica da escola, não podem ignorar completamente o fato de que ela pode apresentar características comuns do transtorno muitas vezes ignoradas pelos mesmos:

Crianças e adultos com TDAH podem mostrar baixa tolerância, frustrações, baixa autoestima e atitudes bruscas, sendo na maioria das vezes considerados pelas pessoas como negligentes e sonhadores, pois iniciam muitos projetos e têm dificuldade para concluí-los. (CARVALHO et al., 2012, p.5). 
Por isso que qualquer ruído diferente no comportamento da mesma deve ser avaliado cuidadosamente. A escola sendo um espaço de experimentos, principalmente diante das primeiras experiências que a criança desenvolve e testa todas suas capacidades intelectuais, físicas e emocionais, acaba se transformando em um cenário em que o aluno exercerá suas habilidades sociais contudo, é nessa hora que começam a aparecer as dificuldades e é a partir desse ponto que a participação da escola e da família são indispensáveis para que se possa detectar as principais características do TDAH.

Não podemos ignorar também o fato de que a família pode ser uma peça fundamental no diagnóstico para que os sintomas do TDAH possam ser amenizados, já que na atualidade ela se designa por laços de respeito, tendo afinidade e afeto, não simplesmente por consanguinidade, mas sim independente do grau de parentesco deve cumprir suas responsabilidades no que diz respeito aos cuidados e proteção diante de seus membros, e não abandoná-los ou deixá-los de lado quando apresentam algum transtorno que possa comprometer seus intelectos ou até mesmo mexer com seus psicológicos.

Alguns alimentos também podem ser muitos eficazes para amenizar os sintomas do transtorno, uma alimentação saudável que possui proporções adequadas de cafeína que em pequenas doses ajuda a criança a manter o foco e a não se dispersar. Alimentos integrais difíceis de ser absorvidos pelo organismo, chás como camomila que ajudam a acalmar, água também vital para nosso corpo, alimentos ricos em ômega 3 e, entre outros, podem contribuir significamente para uma melhora no quadro de quem apresenta o TDAH, porém não tira o comprometimento da família em procurar ajuda de um profissional para que a criança seja tratada, "devido ainda ser controversa a questão alimentar e o portador de TDAH, não se justifica uma restrição radical. Porém a atenção dos pais e familiares não deve ser descartada" (CARVALHO et al., 2012, p. 4).

Outro ponto importante para ajudar na melhora do quadro, seria a própria aceitação do aluno como ele realmente é, ou seja, ele deve aceitar que possui algumas dificuldades causadas pelo transtorno, embora isso não o deixe diferente diante das outras crianças, mas sim o deixa mais determinado em vencer as barreiras que o bloqueiam diante da sua aprendizagem. Com isso, o professor e os familiares devem possibilitar 
às crianças com TDAH resoluções para seus problemas, confusões, ou desentendimentos, sempre ficando atentos e pontuando a capacidade que o mesmo possui diante de diferentes situações.

Estudos mostram que parentes de portadores de TDAH têm maior probabilidade de apresentar este transtorno. Criança com idade escolar tem cerca de $5 \%$ de chance de ser portadora. Irmãos de portadores têm $30 \%$ de chance de apresentarem o transtorno. Quando um dos pais for portador, têm 50\% de chance de ter filhos com o transtorno. (CARVALHO et al. 2012, p.7).

É necessário ficarmos atentos a qualquer comportamento suspeito que a criança apresente dentro da sala de aula que possa estar diretamente ligado com o TDAH, ainda muito mais se a família da criança já tiver alguém diagnosticado com o transtorno, já que as chances da criança desenvolver o mesmo nesse caso são muito maiores.

Muitas vezes, quando os pais são alertados sobre o possível transtorno que a criança pode ter, mediante a todos os diagnósticos possivelmente feitos pelo professor, ainda ocorre um descarte na procura de um especialista para comprovar as suspeitas, já que não há uma aceitação dos familiares pelo possível problema presente na criança, chegando até mesmo a pensar e a falar que quando a criança ou o adolescente permanece em frente de um computador ela se concentra, questionando as observações do professor e da equipe pedagógica da escola. Dessa forma, a postura adquirida pela família é totalmente contrária do que os responsáveis pelas crianças com TDAH deveriam ter.

O caminho em parceria com a escola, buscando um diálogo claro com o professor e com a equipe pedagógica, entrelaçando-se em comunhão com a instituição, sem dúvidas nenhuma pode ser o melhor caminho para proporcionar à criança, que necessita de um tratamento diferenciado das outras mediante ao processo de ensino-aprendizagem, uma educação que se adeque as necessidades dos mesmos, destacando-se por ser de qualidade, para que todos consigam crescer dentro da sabedoria e autonomia, principalmente por parte das crianças.

A família é fundamental para tentar combater o transtorno presente no aluno, porém mesmo não ignorando suas funções diante do fato, 
a responsabilidade perante a criança também se dá pela sociedade e pelo Estado, como está contido na Constituição Federal da República Brasileira, mediante esse fato existe um conjunto de responsabilidades perante a integridade mental e física de uma criança ou adolescente, principalmente daqueles que possuem TDAH.

\section{CONSIDERAÇÕES FINAIS}

A partir das informações obtidas por meio deste trabalho, é possível concluir que o TDAH, caracteriza-se por desatenção, impulsividade e hiperatividade. Os portadores dessa síndrome apresentam dificuldades no que tange em monitorar o tempo, tomar iniciativas, planejar, manter-se motivado, concluir tarefas e autocontrolar-se, é desorganizado tanto internamente como externamente e a impulsividade domina seu comportamento, apresentando inúmeros pensamentos e ideias ao mesmo tempo, um transtorno que vem aparecendo com muita frequência e afetando muitas pessoas hoje em dia.

A falta de diagnóstico e tratamento correto geram grandes prejuízos na vida profissional, social, pessoal e afetiva da criança, adolescente e adulto que apresente o devido transtorno, mas que podem ser revertidos na infância mesmo, tendo o professor como aliado em seu diagnóstico junto da família do indivíduo, principais ferramentas no processo amenização das consequências adquiridas nas pessoas diagnosticada com TDAH adquiridas por tratamentos corretos e estimulantes do processo de ensino-aprendizagem.

\section{REFERÊNCIAS}

BARKLEY, R. A. Transtorno de déficit de atenção/hiperatividade: manual para diagnóstico e tratamento. 3. ed. Porto Alegre: Artmed, 2008.

BARKLEY, R.; GORDON, M. Research on comorbidity, adaptive functioning, and cognitive impairments in adults with ADHD: implications for a clinical practice. In: . Clinicians1 guide to adult ADHD: assessment and intervention. Florida: Academic Press, 2002. p. 43-69. 
BIEDERMAN, J.; MICK, E.; FARAONE, S. V. Age-dependent decline of symptoms of attention deficit hyperactivity disorder: impact of remission definition and symptom type. American journal of psychiatry, v. 157 , n. 5, p. 816-818, 2000.

CARVALHO, A. J. et al. TDAH: considerações sobre o transtorno de déficit de atenção e hiperatividade. Revista Científica do ITPAC, Araguaína, v. 5, n. 3, jul. 2012.

CERVO, A.; BERVIAN, P. A.; SILVA, R. da. Metodologia científica. 6. ed. São Paulo: Pearson Prentice Hall, 2007.

CERVO, A. L.; BERVIAN, P. A. Metodologia científica: para uso dos estudantes universitários. São Paulo: McGraw-Hill do Brasil, 1983.

MATTOS, P. et al. Adaptação transcultural para o português da escala Adult Self-Report Scale para avaliação do transtorno de déficit de atenção/hiperatividade (TDAH) em adultos. Rev. Psiq. Clín. v. 33, n. 4, p. 188-194, 2006.

MATTOS, P. et al. Painel brasileiro de especialistas sobre diagnóstico do transtorno de déficit de atenção/hiperatividade (TDAH) em adultos. Revista Psiquiatra RS, v. 28, n. 1, p. 50-60, jan./abr. 2006.

MCGOUGH, J. J.; BARKLEY, R. A. Diagnostic controversies in adult attention deficit hyperactivity disorder. American Journal of Psychiatry, v. 161, p. 1948-1956, 2004.

MELLO, F. A.; CARDOSO, J. M. Transtorno de déficit de atenção e hiperatividade (TDAH), 2015. Disponível em: <www.portaleducacao. com.br/contudo/artigos/pedagogia/transtorno-do-defict-de-atencao-ehiperatividade-tdah/67753>.

POSSA, M. A.; SPANEMBERG, L.; GUARDIOLA, A. Comorbidades do transtorno de déficit de atenção e hiperatividade em crianças escolares. Arq. Neuro-Psiquiatr. vol. 63, n. 2b. p. 479-483. 2005.

ROHDE, A. L.; HALPERN, R. Transtorno de déficit de atenção/ 
hiperatividade: atualização. Jornal de Pediatria, v. 80, n. 2 (supl), 2004.

SILVA, A. B. Mentes inquietas: TDAH; desatenção, hiperatividade e impulsividade. Rio de Janeiro: Objetiva, 2009.

VASCONCELOS, M. et al. Prevalência do transtorno de déficit de atenção/hiperatividade numa escola pública primária. Arq Neuropsiquiatr. v. 61, n. 1, p. 67-73, 2003.

Recebido em: 17/11/2016 Aprovado em: 28/03/2017 